\title{
Polymyalgia Rheumatica and Thyroid Papillary Carcinoma
}

\author{
Masako TABAtA and Tetuo KoBAYASH*
}

\begin{abstract}
This is a case report of a 64-year-old woman with polymyalgia rheumatica (PMR) and thyroid papillary carcinoma. Peripheral blood lymphocyte response to pokeweed mitogen, concanavalin $A$ and phytohemagglutinin was increased compared to controls during aggravation of PMR. These responses were normalized to control values after low-dose corticosteroid therapy (prednisolone $10 \mathrm{mg} ; 7$ days and $7.5 \mathrm{mg} ; 3$ days) and PMR symptoms disappeared. The patient had undergone total neck thyroidectomy and metastatic neck lymph node dissection three and six years after the onset of PMR, respectively. Nine months after the removal of metastatic lymph nodes, she was free of symptoms of PMR and peripheral blood lymphocyte response to mitogens was within the control range. PMR appeared to be a component of the long-standing paraneoplastic syndrome, induced by the tumor which had impaired cell-mediated immunity.

(Internal Medicine 33: 41-44, 1994)
\end{abstract}

Key words: polymyalgia rheumatica (PMR), thyroid cancer

\section{Introduction}

Polymyalgia rheumatica (PMR), a syndrome in elderly patients, is characterized by pain and stiffness of the shoulder and hip girdles. It is often associated with systemic features such as morning stiffness, general fatigue, low grade fever, anemia and weight loss. The etiology remains unknown. A racial difference exists; the disease is preponderant in Caucasians (3). Case reports of familial aggregation show hereditary predisposition in addition to environmental factors (4). Studies on the association of HLA antigens indicate HLA-DR and CW3 occur with PMR more commonly than predicted by chance (5, 6). The association of PMR with aging may provide some indication of the etiology. Aging and its associated dysregulation in the immune system may allow PMR to occur in response to various stimulations. Cimmino et al (7) reported summer clustering of PMR and speculate PMR to possibly be triggered by such factors as actinic damage of superficial vessels or infective agents which accompany a seasonal cycle. PMR usually follows a benign course with almost complete response to adequate treatment $(3,8)$. There are several reports, however, suggesting that the course of PMR may not be as short and simple as once thought $(2,9-11)$. Occult malignancies accompanied by PMR and a patient with PMR, and thyroid cancer are considered in the present paper.

\section{Case Report}

A 64-year-old woman, who had lived in Edazima (about 15 $\mathrm{km}$ from Hiroshima) and saw the explosion of the atomic bomb in 1945, was healthy apart from an episode of urolithiasis in 1984. Since January 1986 , she experienced easy fatigability and three-kg weight loss over three months. After she contracted influenza-like flu April 1986, she developed myalgia of the hip girdle and proximal lower limbs, followed by proximal upper limb myalgia, low-grade fever, appetite loss and general fatigue. She found it difficult to sit up in bed; she was admitted to the Fukutoku-Igakukai Hospital on July 30, 1986 (Fig. 1). Physical examination indicated a small $(1.5 \mathrm{~cm} \times 1.5 \mathrm{~cm})$ elastic smooth mass in the right anterior cervical area near the midline, two-finger breadths above the clavicle. Muscle strength was decreased in the thigh, shoulder and hip girdles mainly due to myalgia. Temporal arteries were well palpable and not tender. Laboratory tests showed moderate normochromic, normocytic anemia $(\mathrm{Hb} ; 9.2 \mathrm{~g} / \mathrm{dl})$, hypoalbuminemia $(2.6 \mathrm{~g} / \mathrm{dl})$, an accelerated erythrocyte sedimentation rate: ESR $(61 \mathrm{~mm} / \mathrm{hr})$, and polyclonal hypergammaglobulinemia (IgG; $2,727 \mathrm{mg} / \mathrm{dl}$ ). Urinalysis, an LE test, complement titers and rheumatoid factor were all within normal ranges or negative (Table 1). An upper gastrointestinal study, intravenous pyelographic examination, ultrasonographic study of the gallbladder and CT scan of the abdomen were negative, except for mild left renal pelvic dilatation. Nonsteroidal anti-inflammatory drugs were prescribed, but had no effect. Her symptoms progressively wors-

From Tabata Clinic and *the Department of 2nd Surgery, Osaka University, Osaka

Received for publication May 18, 1993; Accepted for publication November 24, 1993

Reprint requests should be addressed to Dr. Masako Tabata, Tabata Clinic, 21 Ogaki-Takigi, Tanabecho, Kyoto 610-03 


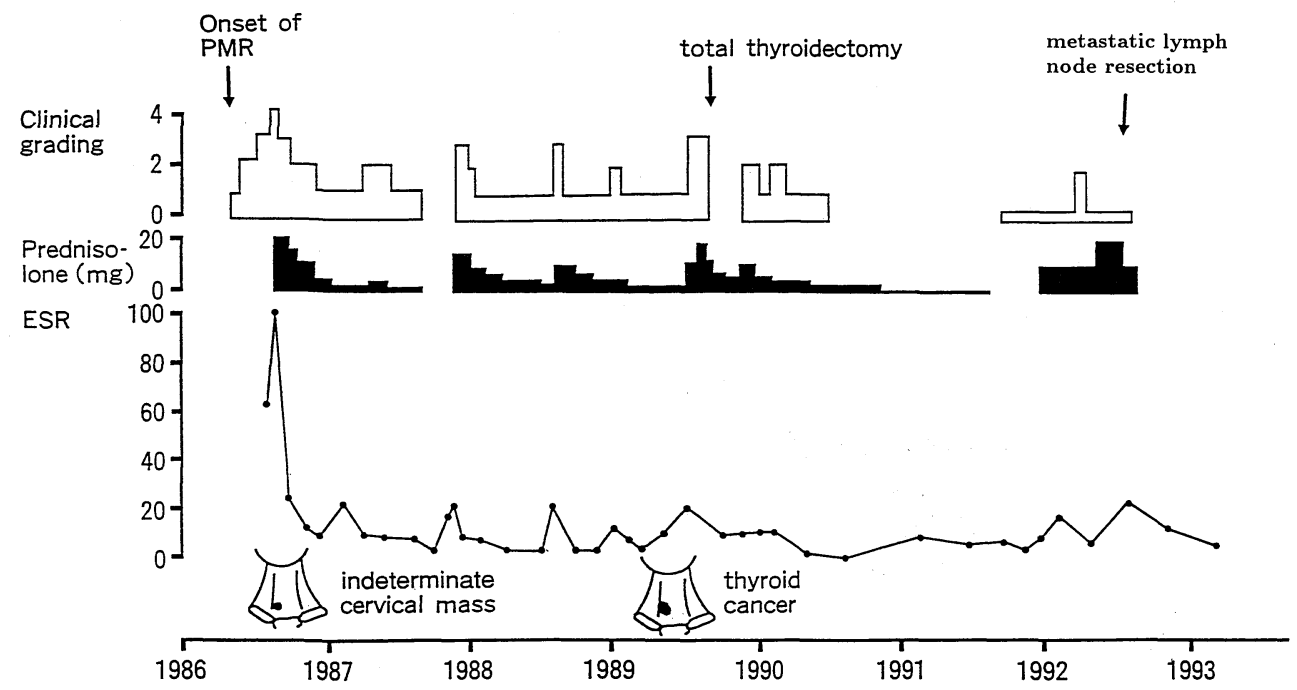

Fig. 1. Graphic demonstration of the patient's clinical course. Clinical grading, as recommended by Gordon, was assessed based on the intensity of muscular symptoms and reduction in mobility. Grade 4: severe pain, markedly reduced mobility of hips and shoulders. Grade 3: moderate pain, reduced mobility of at least one large joint. Grade 2: mild but constant pain, normal mobility. Grade 1: mild transient pain, occasionally requiring analgesics $(1,2)$.

Table 1. Laboratory Findings on Admission

\begin{tabular}{|c|c|c|c|c|c|}
\hline \multicolumn{6}{|c|}{ 1. Peripheral blood } \\
\hline \multirow{6}{*}{1.} & WBC & $5,700 / \mathrm{mm}^{3}$ & & Creatinine & $0.5 \mathrm{mg} / \mathrm{dl}$ \\
\hline & $\mathrm{RBC}$ & $339 \times 10^{4} / \mathrm{mm}^{3}$ & & UA & $3.8 \mathrm{mg} / \mathrm{dl}$ \\
\hline & $\mathrm{Hb}$ & $9.2 \mathrm{~g} / \mathrm{dl}$ & & $\mathrm{Na}$ & $137 \mathrm{mEg} / \mathrm{L}$ \\
\hline & $\mathrm{Ht}$ & $28.7 \%$ & & K & $4.0 \mathrm{mEq} / \mathrm{L}$ \\
\hline & Platelets & $39.2 \times 10^{4} / \mathrm{mm}^{3}$ & & $\mathrm{Cl}$ & $99 \mathrm{mEq} / \mathrm{L}$ \\
\hline & ESR & $61 \mathrm{~mm} / \mathrm{hr}$ & & $\mathrm{Ca}$ & $3.7 \mathrm{mEq} / \mathrm{L}$ \\
\hline \multirow{5}{*}{2.} & & $107 \mathrm{~mm} / 2 \mathrm{hrs}$ & & Blood Glucose & $102 \mathrm{mg} / \mathrm{dl}$ \\
\hline & CRP & $(4+)$ & & Myoglobin & $19.6 \mathrm{ng} / \mathrm{ml}$ \\
\hline & & $6.80 \mathrm{mg} / \mathrm{dl}$ & & Aldolase & $5.5 \mathrm{U}$ \\
\hline & Sialic acid & $109 \mathrm{mg} / \mathrm{dl}$ & 4. & Serology & \\
\hline & Fibrinogen & $493 \mathrm{mg} / \mathrm{dl}$ & & IgG & $2,727 \mathrm{mg} / \mathrm{dl}$ \\
\hline \multirow[t]{14}{*}{3.} & Blood Chemistry & & & IgA & $420 \mathrm{mg} / \mathrm{dl}$ \\
\hline & T.P. & $6.9 \mathrm{~g} / \mathrm{dl}$ & & IgM & $103 \mathrm{mg} / \mathrm{dl}$ \\
\hline & Alb. & $2.6 \mathrm{~g} / \mathrm{dl}$ & & RA & $(-)$ \\
\hline & $\mathrm{A} / \mathrm{G}$ ratio & 0.74 & & HBsAg & $(-)$ \\
\hline & GOT & $13 \mathrm{~K} . \mathrm{U}$ & & $\mathrm{HBsAb}$ & $(+)$ \\
\hline & GPT & $11 \mathrm{~K} . \mathrm{U}$ & & LE test & $(-)$ \\
\hline & ALP & 42K.A. & & $\mathrm{CH}_{50}$ & $36.6 \mathrm{U}$ \\
\hline & $\gamma$-GTP & $24 \mathrm{IU} / 1$ & & $\mathrm{C}_{3}$ & $100 \mathrm{mg} / \mathrm{dl}$ \\
\hline & LAP & $130 \mathrm{U}$ & & $\mathrm{C}_{4}$ & $37 \mathrm{mg} / \mathrm{dl}$ \\
\hline & Ch-E & $0.62 \Delta \mathrm{pH}$ & 5. & $B_{2}-\mathrm{MG}$ & $1.77 \mathrm{mg} / \mathrm{L}$ \\
\hline & LDH & 224 IU/L & & $\alpha$-Fetoprotein & $5.1 \mathrm{ng} / \mathrm{ml}$ \\
\hline & $\mathrm{CPK}$ & $23 \mathrm{IU} / \mathrm{L}$ & & CEA-s & $1.2 \mathrm{ng} / \mathrm{ml}$ \\
\hline & T-Chol & $138 \mathrm{mg} / \mathrm{dl}$ & & CA19-9 & $6 \mathrm{U} / \mathrm{ml}$ \\
\hline & HDL-Chol & $28 \mathrm{mg} / \mathrm{dl}$ & 6. & Urinalysis & W.N.L. \\
\hline
\end{tabular}

ened and she could not sit up in bed without help. A tentative diagnosis of PMR was made. Prednisolone (20 mg daily) was started from August 10,1986 and led to rapid relief of muscular symptoms. Six days after starting steroid therapy she felt well and could sit up in bed and walk well. Ten days after prednisolone therapy was begun, ESR was $22 \mathrm{~mm} / \mathrm{hr}$, Hb was $11 \mathrm{~g} / \mathrm{dl}$, and serum albumin was $3.2 \mathrm{~g} / \mathrm{dl}$. She was discharged on prescription of prednisolone (15 mg/day). Prednisolone was gradually tapered and discontinued after 7 months. PMR symptoms recurred and prednisolone (15 mg/day) was reinstituted. PMR relapsed six times over a three-year period and she required low-dose corticosteroid (prednisolone 10-15 mg/day) for the control of muscular symptoms. In April 1989, her physician recognized a cervical mass which was $2 \times 2 \mathrm{~cm}$ and moved when swallowing. Plain X-rays of the neck demonstrated coarse and shell-like calcifications. CT scan of the thyroid showed a relatively homogenous low density mass (Fig. 2). A fine-needle aspiration biopsy of the thyroid showed papillary cell carcinoma. She had total neck thyroidectomy in July 1989. Contrary to frequent relapse before the operation, PMR was completely remitted after thyroidectomy for 14 months without steroid therapy. PMR, however, recurred again from Nov. 1991, 28 months after thyroidectomy, and prednisolone was prescribed from April 21, 1992 (Fig. 1). Table 2 shows lymphocyte phenotype frequency before and after steroid therapy (prednisolone; $10 \mathrm{mg} /$ day for seven days and then $7.5 \mathrm{mg} /$ day for three days). There was a prompt response from stage 3 Gordon to stage 0 Gordon after therapy, but peripheral blood lymphocyte phenotype frequency did not change; there was an increase in CD4, CD25 and LEU-HLA DR frequency. In contrast, the lymphocyte stimulation test on mitogens most sensitively reflected the clinical stage of PMR. Though phytohemagglutinin (PHA), concanavalin A (Con A), pokeweed mitogen (PWM) stimulated responses, all showed more than 1.5- to 2-fold the upper limit of control values before therapy, they were within the control range after the ten-day prednisolone therapy (Fig. 3). Left cervical lymph node metastases were recognized in June 1992, six months after the postoperative 


\section{CT Scan of the Thyroid}
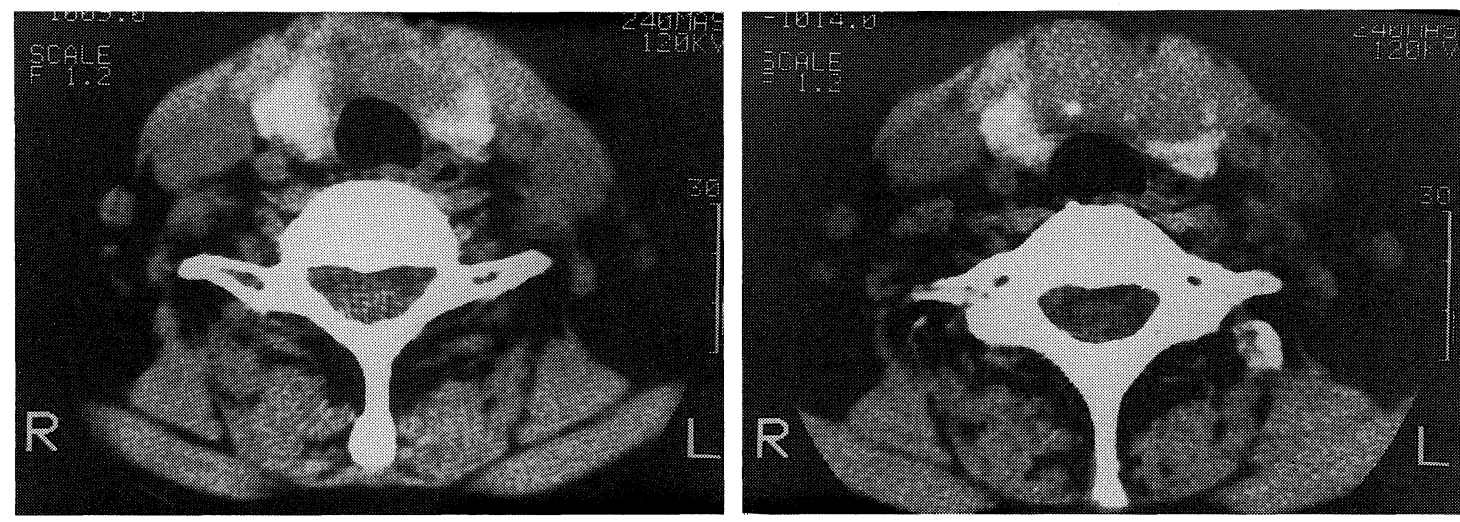

Fig. 2. Relatively homogeneous low density mass in the thyroid gland, extending over both lobes and accompanied by calcification.

Table 2. Lymphocyte Phenotype Frequencies Before and After Corticosteroid

\begin{tabular}{lccc}
\hline & \multicolumn{3}{c}{$\%$ total lymphocytes positive } \\
\hline Phenotype & Before Tx. & After Tx. & Control \\
& & & \\
CD3 & 82.7 & 79.2 & $54.4-73.0$ \\
CD4 & 58.7 & 54.6 & $32.3-48.7$ \\
CD8 & 26.6 & 24.1 & $18.8-32.6$ \\
CD4 : CD8 & 2.21 & 2.27 & $1.54-1.94$ \\
CD16 & 10.2 & 8.3 & $11.4-23.6$ \\
CD20 & 5.9 & 10.0 & $5.0-14.0$ \\
CD25 & 6.6 & 7.2 & 0 \\
CD57 & 27.3 & 25.1 & $7.6-26.0$ \\
LUE HLA-DR & 32.6 & 31.7 & $7.0-15.0$ \\
\hline
\end{tabular}

relapse of PMR. She was reoperated on for resection of metastatic lymph nodes on July 14, 1992. Since then, PMR has continued to be completely remitted to April 1993. Lymphocyte stimulation test (PHA and PWM; Con A was not determined) continued to be within the normal range in March 1993 (data not shown).

\section{Discussion}

The definition of PMR has been formalized (3) (Table 3). Patients are usually older than 50 years and Caucasians are most often affected. Symptoms include symmetrical aching involving two of the three following areas: the neck, the shoulder girdle, and the hip girdle. The aching is present for greater than one month. Evidence for systemic inflammation is usually present with an erythrocyte sedimentation rate of greater than $40 \mathrm{~mm} / \mathrm{hr}$ by the Westergren method. The presence of a concomitant systemic inflammatory disease other than giant cell arteritis excludes the diagnosis of PMR (3). A dramatic and rapid response to small doses of corticosteroid, less than $15 \mathrm{mg} /$ day prednisolone or equivalent, is characteristic of PMR. Polymyalgia rheumatica traditionally follows a benign course with almost complete response to an adequate treatment pro-

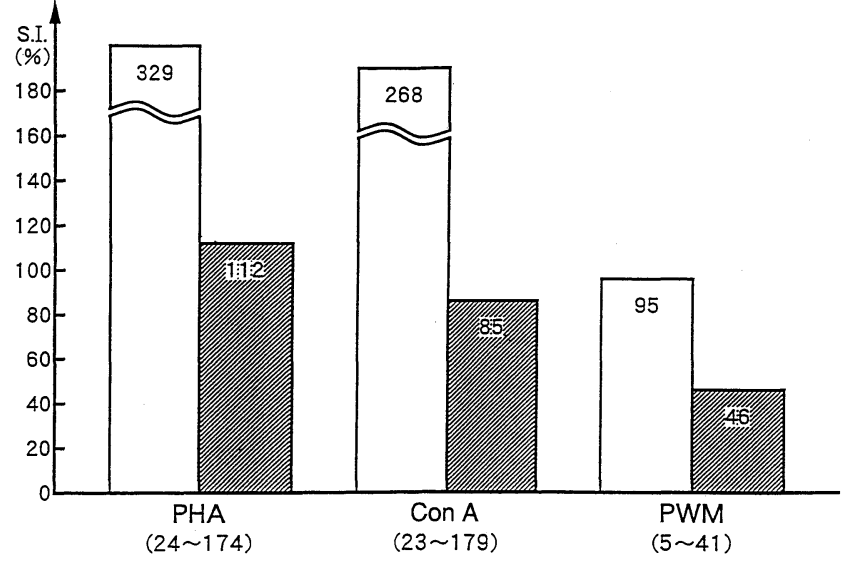

Fig. 3. Lymphocyte stimulation test before ( $\square$ ) and after ( $\square$ ) corticosteroid therapy. PHA: phytohemagglutinin, Con A: concanavalin A, PWM: pokeweed mitogen. S.I. denotes stimulation index. Figures in parentheses show S.I. of control value.

Table 3. Definition of Polymyalgia Rheumatica (3)

1. Patient older than 50 years.

2. Bilateral pain for at least one month involving two of the following: neck, shoulder girdle, and hip girdle, associated with morning stiffness and gelling.

3. Erythrocyte sedimentation rate of greater than $40 \mathrm{~mm} / \mathrm{hr}$.

4. Exclusion of other diagnoses except giant cell arteritis.

5. Lesser criteria: Causasian race, evidence for a systemic illness, no evidence of primary muscle disease or infection, clinical synovitis, a clinical response to corticosteroids in dosages less than or equal to a prednisone equivalent of $15 \mathrm{mg}$ / daily. 
gram. Life expectancy in PMR is not impaired (11). Recently, there are several reports suggesting that the course of PMR may not be as short and simple as once thought. Ayoub WT et al (9) examined 76 patients with PMR without evidence of temporal arteritis at presentation. Seventy-five patients received corticosteroids, with a mean prednisone dosage of $22.8 \mathrm{mg}$ per day initially. The median duration of therapy was 37.3 months. It was estimated that $40 \%$ of patients would require therapy longer than four years. Their data support the concept of two patient populations; one with limited disease and another requiring lon-term therapy. Polymyalgia rheumatica has been reported in conjunction with several malignancies $(3,10,11)$, usually cancers of the breast or gastrointestinal malignancies. Except for one series of cases of whom 17\% had neoplasms (14), the general experience has been a coincidence of about $3 \%$ which, with rare exceptions, is attributed to chance (11). Undoubtedly, occasional cases of PMR are clearly associated with neoplasms displaying themselves as paraneoplastic behavior (10). Dermatomyositis may precede the occurrence of neoplasms by many years. In the patient under consideration, typical polymyalgia rheumatica developed when thyroid papillary carcinoma (cervical mass) had already existed. Thyroid papillary carcinoma can be clinically silent for many years or even decades (Occult thyroid Carcinoma: OTC) (15). The dramatic and prompt relief of the symptoms was achieved every time in response to corticosteroid treatment and the recurrence of neoplasm coincided in time with the polymyalgic syndrome. After resection of metastatic lymph nodes, PMR symptoms disappeared and never recurred until this writing. The etiology of PMR remains unknown. The association of PMR with aging suggests that an age-dependent depression of Tlymphocyte function leads to the onset of PMR, secondary to various stimulations, which include infectious agents, actinic rays (7) and neoplasms. The T cell system may be induced to produce excessive lymphokines (eg, interferon) by various mechanisms (12). These may include (1) tumorassociated antigens nonspecifically stimulating leukocytes, (2) tumor-associated antigens specifically targeted to stimulate leukocytes and/or (3) deregulation of the leukocyte gene pool, with a subsequent release of previously suppressed lymphokines (13). In this case, activated T cell subsets were shown by elevated frequency of CD4, CD25 (interleukin-2 receptor bearing activated T cell) and LEU HLA-DR (also a marker of T cell activation) subsets, and may be an indication of long-standing paraneoplastic manifestation and may be related to the onset and development of PMR. The possibility of an underlying malignancy should be kept in mind even in long-standing cases of PMR with good primary response to proper therapy. Frequent relapse to rheumatic symptoms during or soon after therapy necessitates an extensive work-up to detect the underlying tumor.

\section{References}

1) Gordon I. Polymyalgia rheumatica. A clinical study of 21 cases. Q J Med 29: $473,1960$.

2) John VK, Olof S. Sarcoidosis with thyroid involvement, polymyalgia rheumatica and breast carcinoma. Scand J Rheumatol 5: 77, 1976.

3) Cohen MD, Ginsburg WW. Polymyalgia rheumatica. Rheum Dis Clin North Am 16: 325, 1990.

4) Liang GC, Simkin PA, Hunder GG, Healey LA. Familial aggregation of polymyalgia rheumatica and giant cell arteritis. Arthritis Rheum 17: 19, 1974.

5) Armstrong RD, Behn A, Myles A, et al. Histocompatibility antigens in polymyalgia rheumatica and giant cell arteritis. J Rheumatica 10: 659, 1983.

6) Calamia KT, Moore SB, Elveback LR, Hunder GG. HLA-DR locus antigens in polymyalgia rheumatica and giant cell arteritis. J Rheumatol 8: 993, 1981.

7) Cimmino MA, Caporali R, Montecucco CM, Rovida S, Baratelli E, Broggini $\mathrm{M}$. A seasonal pattern in the onset of polymyalgia rheumatica. Ann Rheum Dis 49: 521, 1990.

8) Chuang TY, Hunder GG, Ilstrup MD, Kurland LT. Polymyalgia rheumatica, a 10 year epidemiologic and clinical study. Ann Intern Med 97: 672, 1982 .

9) Ayoub WT, Franklin CM, Torretti D. Polymyalgia rheumatica. Duration of therapy and long-term outcome. Am J Med 79: 309, 1985.

10) von Knorring J, Somer T. Malignancy in association with polymyalgia rheumatica and temporal arteritis. Scand J Rheumatol 3: 129, 1974.

11) Benedek TG. Neoplastic associations of rheumatic diseases and rheumatic manifestations of cancer. Clin Geriatr Med 4: 333, 1988.

12) Averbuch SD, Austin HA, Sherwin SA, et al. Acute interstitial nephritis with the nephrotic syndrome following recombinant leukocyte A interferon therapy for mycosis fungoides. N Engl J Med 310: 32, 1984.

13) Whelan TV, Hirszel P. Minimal-change nephropathy associated with pancreatic carcinoma. Arch Intern Med 148: 975, 1988.

14) Fauchald $P$, Rygvold $O$, Oystese B. Temporal arteritis and polymyalgia rheumatica. Ann Intern Med 77: 845, 1972.

15) Collins SL. Etiopathogenesis of thyroid cancer. in: Thyroid Disease, Falk S, Ed. Raven Press, New York, 1990, p.428. 